\title{
Plant Growth-Promoting Rhizobacteria Improved Salinity Tolerance of Lactuca sativa and Raphanus sativus
}

\author{
Khalid Abdallah Hussein ${ }^{1,2}$ and Jin Ho Joo ${ }^{2 *}$ \\ ${ }^{1}$ Department of Botany and Microbiology, Faculty of Science, Assiut University, Assiut 71516, Egypt \\ ${ }^{2}$ Department of Biological Environment, Kangwon National University, Chuncheon 24341, Republic of Korea
}

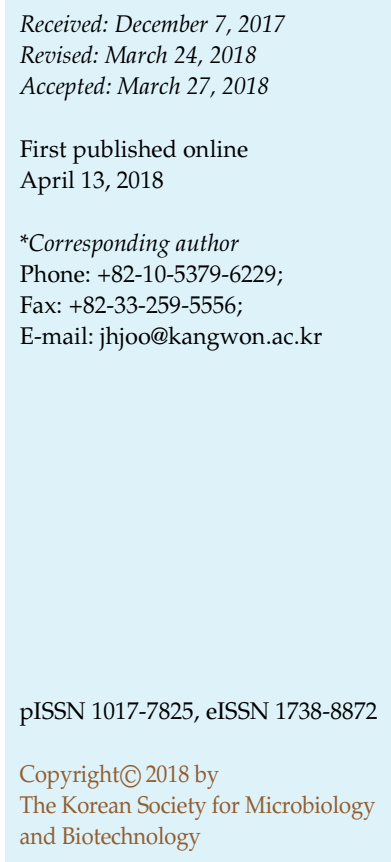

Salinity stress is an important environmental problem that adversely affects crop production by reducing plant growth. The impacts of rhizobacterial strains to alleviate salinity stress on the germination of Lactuca sativa and Raphanus sativus seeds were assessed using different concentrations of $\mathrm{NaCl}$. Plant growth-promoting rhizobacteria (PGPR) strains were also examined to improve the early germination of Chinese cabbage seeds under normal conditions. Lactobacillus sp. and P. putida inoculation showed higher radicle lengths compared with non-inoculated radish (Raphanus sativus) seeds. LAP mix inoculation increased the radicle length of lettuce (Lactuca sativa) seedlings by 2.0 and $0.5 \mathrm{~cm}$ at salinity stress of 50 and $100 \mathrm{mM} \mathrm{NaCl}$ concentration, respectively. Inoculation by Azotobacter chroococcum significantly increased the plumule and radicle lengths of germinated seeds compared with non-inoculated control. A. chroococcum increased the radicle length relative to the uninoculated seeds by 4.0, 1.0 , and $1.5 \mathrm{~cm}$ at 50,100 , and $150 \mathrm{mM} \mathrm{NaCl}$ concentration, respectively. LAP mix inoculation significantly improved the radicle length in germinated radish seeds by $7.5,1.3,1.2$, and $0.6 \mathrm{~cm}$ under salinity stress of $50,100,150$, and $200 \mathrm{mM} \mathrm{NaCl}$ concentration, respectively. These results of this study showed that PGPR could be helpful to mitigate the salinity stress of different plants at the time of germination.

Keywords: PGPR, stress mitigation, microbial inoculation, early seed germination

\section{Introduction}

The severity of abiotic stresses, particularly salinity, disturbs perspectives of crop production. Ecological stresses are the most restricting aspects to seed germination [1, 2]. Salinity is an abiotic stress common in arid and semiarid regions that substantially declines the yield of crops by more than $50 \%$ [3]. Recently, high soil salinity became a very serious factor limiting the agricultural production in a wide proportion over the world [4]. Failure of germination on saline soils is often due to a high salt level in the planting zone as well as upward movement of the soil solution and subsequent evaporation at the soil surface [5]. Moreover, ethylene stress occurs, in which ethylene is biosynthesized by the plant as a response to these stresses [3]. This ethylene stress induces the symptoms of senescence in the plant, such as abscission and chlorosis, which affect plant growth and survival [6]. Some rhizobia strains can produce the enzyme 1-aminocyclopropane-1-carboxylate deaminase (ACCD), which hydrolyzes the ethylene precursor (ACC) in plants [7]. Consequently, ACCD-producing bacteria may improve plant growth by declining the malicious impacts of ethylene stress. Glick [8] demonstrated that ACCD can be produced by numerous rhizobacterial strains. Moreover, plant growth-promoting rhizobacteria (PGPR) can enhance plant growth by different direct and indirect mechanisms [9]. One of these mechanisms is elevating the plant tolerance to dry condition, salinity, and metal toxicity. Therefore, the rhizobacterial population is the main source for effective microorganisms that can improve plant survival under different abiotic stresses, such as drought and salinity, through several mechanisms [10]. Increasing plant hormone synthesis, such as of indole acetic acid (IAA) and gibberellins, is the main trigger of the 
activity of specific enzymes that promote seed germination and growth [11]. Thus, PGPR were found to endure salinity stress, which are frequently harmful to the growth of essential crop plants [12]. The aim of the present work was to demonstrate the adverse effect of salinity on plant growth and to report the potentiality of rhizobacterial strains to mitigate this effect on the early seed germination of Lactuca sativa and Raphanus sativus.

\section{Materials and Methods}

\section{Microorganisms and Inocula}

Microorganisms that strongly produce IAA were previously isolated from the rhizosphere of Panax schinseng (ginseng plant) South Korea [13]. The bacterial strain cultures were activated in Tryptic soy agar (TSA) medium, pH 7.2. Optical density was used to control the inoculum size in liquid media. Specifically, $1 \mathrm{ml}$ of the newly growing spores $\left(1 \times 10^{6} \mathrm{CFU} / \mathrm{ml}\right)$ were transferred to $250 \mathrm{ml}$ of fresh TSB liquid medium supplemented with $(5 \%) \mathrm{NaCl}$ and incubated at $30^{\circ} \mathrm{C}$ for $48 \mathrm{~h}$.

\section{Effect of $\mathrm{NaCl}$ Stress on Seed Germination}

Plant seeds were surface disinfected by immersing in $70 \%$ ethanol for $1 \mathrm{~min}$, and then washed three times in sterile distilled water. Ten seeds were set for every Petri dish lined with filter paper (Whatman No. 1) wetted by $5 \mathrm{ml}$ of $0,50,100$, and $150 \mathrm{mM}$ of sterile $\mathrm{NaCl}$ solution. The experiments were run intriplicate. All Petri dishes of various treatments were incubated at $28^{\circ} \mathrm{C}$ under darkness in a plant growth chamber (DASOL; Scientific Co., Ltd., Korea). Germination development was checked for 4 days. The number of germinated seeds was recorded after every $24 \mathrm{~h}$.

\section{Seed Inoculation}

The bacterial spore suspension was adjusted into $1 \times 10^{7} \mathrm{CFU} / \mathrm{ml}$ for all actively growing culture using a UV-VIS Spectrophotometer (Hitachi U-2900) and OD at $600 \mathrm{~nm}$. The inocula levels were calibrated to reach a turbidity of $0.4 \mathrm{McF}$ arland Standard (matches approximately $5 \times 10^{7} \mathrm{CFU} / \mathrm{ml}$ ) [14]. Seeds were agitated at $150 \mathrm{rpm}$ with their spore suspension for $2 \mathrm{~h}$ at room temperature. The seeds were separated from the spore suspension using sterile tea mesh sieves and set as 10 seeds/dish [15]. The seeds were placed on sterile filter paper (Whatman No. 1) that had been moistened by $5 \mathrm{ml}$ of sterile distilled water. The trial was conducted in triplicate.
Table 1. Seed germination percentages of Brassica rapa, Lactuca sativa, and Raphanus sativus under different salinity levels after $96 \mathrm{~h}$.

\begin{tabular}{cccr}
\hline \multirow{2}{*}{\begin{tabular}{c} 
NaCl treatment $(\mathrm{mM})$ \\
\cline { 2 - 4 }
\end{tabular}} & $\begin{array}{c}\text { Chinese } \\
\text { cabbage }\end{array}$ & Lettuce & Radish \\
\hline Control & $100 \pm 0.707 \mathrm{a}$ & $100 \pm 0 \mathrm{a}$ & $100 \pm 1.41 \mathrm{a}$ \\
50 & $100 \pm 0.353 \mathrm{a}$ & $100 \pm 0 \mathrm{a}$ & $80 \pm 1.41 \mathrm{a}$ \\
100 & $95 \pm 0.353 \mathrm{a}$ & $75 \pm 0.71 \mathrm{ab}$ & $80 \pm 1.41 \mathrm{a}$ \\
150 & $90 \pm 0.707 \mathrm{a}$ & $0.00 \pm 0 \mathrm{c}$ & $80 \pm 1.41 \mathrm{a}$ \\
200 & $90 \pm 0.707 \mathrm{a}$ & $0.00 \pm 0 \mathrm{c}$ & $50 \pm 1.41 \mathrm{~b}$ \\
\hline
\end{tabular}

Different letters indicate significant difference $(p<0.05)$ between control and $\mathrm{NaCl}$ treatments.

\section{Seeds Inoculation under Salinity Conditions}

The seed germination test under different salinity levels of $\mathrm{NaCl}(50,100$, and $150 \mathrm{mM})$ was conducted under single- and multi-inoculated conditions. The seed surface was disinfected and washed as stated above. Seeds were inoculated by dipping for $2 \mathrm{~h}$ in $30 \mathrm{ml}$ of their bacterial spore suspension $\left(1 \times 10^{7} \mathrm{CFU} / \mathrm{ml}\right)$ under shaking condition of $150 \mathrm{rpm}$. In the multi-inoculated treatment, $10 \mathrm{ml}$ of every culture were added to make the spore suspension. Sterile distilled water was used instead of spore suspension to serve as a control. Using the sterile mesh sieve, 10 seeds were separated and each placed in a Petri dish lined by sterile filter paper (Whatman No. 1) [15]. Salinity and/or moisture conditions were provided by adding $5 \mathrm{ml}$ of the sterile $0,50,100$, and $150 \mathrm{mM} \mathrm{NaCl}$ solution. The germination percentage (\%) was calculated according to kader's [16] equation (Germination \% = (Number of germinated seeds/Total number of seeds) $\times 100$ ).

\section{Statistical Analysis}

Data were subjected to the analysis of variance. Significance at the $5 \%$ level was verified by least significant difference by means of the Statistical Analysis Software (SAS) ver. 9.1 program [17].

\section{Results}

Stress tolerance due to microbial inoculants has become of great interest to plant and soil scientists. In the present study, the germination of Lactuca sativa and Raphanus sativus

Table 2. Effect of PGPR on seed germination of lettuce Lactuca sativa under different salinity levels.

\begin{tabular}{|c|c|c|c|c|c|}
\hline \multirow{2}{*}{$\mathrm{NaCl}(\mathrm{mM})$} & \multicolumn{5}{|c|}{ Germination rate $(\%)$} \\
\hline & Control & A. chroococcum & Lactobacillus sp. & P. putida & LAP mix \\
\hline 50 & $100 \pm 0 a$ & $100 \pm 0 \mathrm{a}$ & $100 \pm 0 \mathrm{a}$ & $100 \pm 0 a$ & $100 \pm 0 \mathrm{a}$ \\
\hline 150 & $0.00 \pm 0 c$ & $95 \pm 0.71 \mathrm{a}$ & $15 \pm 0.71 c$ & $0.00 \pm 0 c$ & $50 \pm 2.83 b$ \\
\hline 200 & $0.00 \pm 0 c$ & $90 \pm 0 a$ & $0.00 \pm 0 c$ & $0.00 \pm 0 c$ & $0.00 \pm 0 c$ \\
\hline
\end{tabular}


Table 3. Effect of PGPR on the root length of lettuce Lactuca sativa under different salinity levels.

\begin{tabular}{clccll}
\hline \multirow{2}{*}{$\mathrm{NaCl}(\mathrm{mM})$} & \multicolumn{5}{c}{ Radicle length (cm/plant) } \\
\cline { 2 - 6 } & Control & A. chroococcum & Lactobacillus sp. & P. putida & LAP mix \\
\hline 50 & $0.43 \pm 0.11 \mathrm{ef}$ & $2.31 \pm 0.24 \mathrm{~b}$ & $1.03 \pm 0.05 \mathrm{c}$ & $0.70 \pm 0.12 \mathrm{de}$ & $2.56 \pm 0.16 \mathrm{a}$ \\
100 & $0.37 \pm 0.21 \mathrm{f}$ & $1.00 \pm 0 \mathrm{~cd}$ & $0.50 \pm 0 \mathrm{ef}$ & $0.50 \pm 0 \mathrm{ef}$ & $0.88 \pm 0.15 \mathrm{~cd}$ \\
150 & $0.00 \pm 0 \mathrm{~g}$ & $0.00 \pm 0 \mathrm{~g}$ & $0.00 \pm 0 \mathrm{~g}$ & $0.00 \pm 0 \mathrm{~g}$ & $0.00 \pm 0 \mathrm{~g}$ \\
200 & $0.00 \pm 0 \mathrm{~g}$ & $0.00 \pm 0 \mathrm{~g}$ & $0.00 \pm 0 \mathrm{~g}$ & $0.00 \pm 0 \mathrm{~g}$ & $0.00 \pm 0 \mathrm{~g}$ \\
\hline
\end{tabular}

seeds under different levels of salinity were checked. Consequently, the effects of some selected PGPR strains to mitigate salinity stress at the early germination process of L. sativa and $R$. sativus plants were studied in laboratory environment. Treatment of $50 \mathrm{mM}$ of $\mathrm{NaCl}$ did not affect the Brassica rapa and L. sativa seed germination; however, the $R$. sativus seed germination rate was reduced to $80 \%$. The salinity of $100 \mathrm{mM}$ of $\mathrm{NaCl}$ also caused $80 \%$ germination of $R$. sativus seeds and decreased the B. rapa seed germination to $95 \%$, and $75 \%$ for L. sativa. The salinity of $200 \mathrm{mM}$ of $\mathrm{NaCl}$ reduced the germination of $R$. sativus by $50 \%$ and only $10 \%$ for B. rapa seeds (Table 1 ).

\section{PGPR Impact on Seed Germination at Different Salinity \\ Stress Levels}

Application of $A$. chroococcum significantly increased the germination rate of L. sativa seeds by $25 \%, 95 \%$, and $90 \%$ at salinity stress of 100,150, and $200 \mathrm{mM}$ of $\mathrm{NaCl}$, respectively, as shown in Table 2. However, the other inoculants showed no significant seed germination at $200 \mathrm{mM}$ of $\mathrm{NaCl}$. LAP mix increased the seed germination by $25 \%$ and $50 \%$ at salinity levels of 100 and $150 \mathrm{mM} \mathrm{NaCl}$, respectively. P. putida inoculation showed no increase higher than control; however, Lactobacillus sp. enhanced the seed germination by $25 \%$ and $15 \%$ at $\mathrm{NaCl}$ stress of 100 and $150 \mathrm{mM}$, respectively (Table 2). LAPmix inoculation increased the radicle length of L. sativa seedling significantly by 2.0 and $0.5 \mathrm{~cm}$ at salinity stress of 50 and $100 \mathrm{mM} \mathrm{NaCl}$, respectively. Similarly, inoculation of $A$. chroococcum increased the radicle length significantly at salinity stress of 50 and $100 \mathrm{mM} \mathrm{NaCl}$ by 1.9 and $0.5 \mathrm{~cm}$, respectively. However, Lactobacillus sp. and P. putida did not show a significant increase in the radicle length at the same salinity levels as compared with the control. All inoculants could not enhance the radicle length at salinity stress of 150 and $200 \mathrm{mM} \mathrm{NaCl}$ (Table 3). Inoculation of A. chroococcum and LAPmix increased the plumule length of L. sativa germinated seed by 2.0 and $2.3 \mathrm{~cm}$ at $50 \mathrm{mM}$ $\mathrm{NaCl}$, respectively (Fig. 1). Lactobacillus sp. inoculation increased the length of plumule by $2.0 \mathrm{~cm}$ at $50 \mathrm{mM} \mathrm{NaCl}$, and by $0.3 \mathrm{~cm}$ at $100 \mathrm{mM} \mathrm{NaCl}$, higher than the control. None of the inoculants increased the L. sativa plumule growth at salinity stresses of 150 and $200 \mathrm{mM} \mathrm{NaCl}$. P. putida inoculation showed the lowest activity to enhance the L. sativa growth (Table 4). R. sativus seed germination
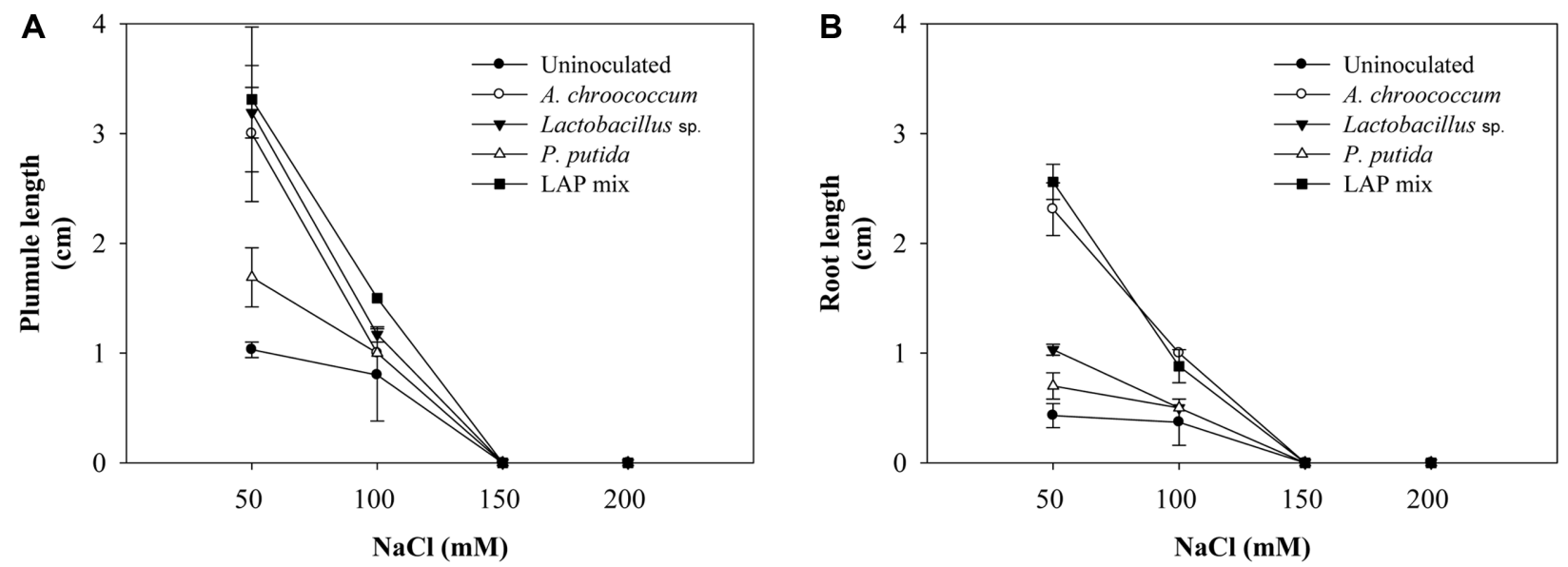

Fig. 1. Bacterial inoculation enhances the salinity tolerance of the stressed Lactuca sativa plant.

(A) Plumule length and (B) root length of lettuce after $96 \mathrm{~h}$ of different salinity stress and bacterial applications. 
Table 4. Effect of PGPR on the plumule length of lettuce Lactuca sativa under different salinity levels.

\begin{tabular}{clcccc}
\hline \multirow{2}{*}{$\mathrm{NaCl}(\mathrm{mM})$} & \multicolumn{5}{c}{ Plumule length (cm/plant) } \\
\cline { 2 - 6 } & Control & A. chroococcum & Lactobacillus sp. & P. putida & LAP mix \\
\hline 50 & $1.03 \pm 0.07 \mathrm{~d}$ & $3.00 \pm 0.62 \mathrm{a}$ & $3.19 \pm 0.23 \mathrm{a}$ & $1.69 \pm 0.27 \mathrm{~b}$ & $3.31 \pm 0.66 \mathrm{a}$ \\
100 & $0.80 \pm 0.42 \mathrm{~d}$ & $1.00 \pm 0 \mathrm{~d}$ & $1.17 \pm 0.07 \mathrm{~cd}$ & $1.00 \pm 0 \mathrm{~d}$ & $1.50 \pm 0 \mathrm{c}$ \\
150 & $0.00 \pm 0 \mathrm{e}$ & $0.00 \pm 0 \mathrm{e}$ & $0.00 \pm 0 \mathrm{e}$ & $0.00 \pm 0 \mathrm{e}$ & $0.00 \pm 0 \mathrm{e}$ \\
200 & $0.00 \pm 0 \mathrm{e}$ & $0.00 \pm 0 \mathrm{e}$ & $0.00 \pm 0 \mathrm{e}$ & $0.00 \pm 0 \mathrm{e}$ & $0.00 \pm 0 \mathrm{e}$ \\
\hline
\end{tabular}

was enhanced under salinity stress by Lactobacillus sp. only at $100 \mathrm{mM} \mathrm{NaCl}$, and by LAP mix inoculation at $200 \mathrm{mM}$ $\mathrm{NaCl}$. Interestingly, all bacterial inoculants could not improve the $R$. sativus seed germination rate significantly (Table 5). The $R$. sativus radicle was greatly enhanced by the help of $A$. chroococcum inoculation, and it further increased the radicle length higher than the uninoculated seeds, by $4.0,1.0$, and $1.5 \mathrm{~cm}$ at $\mathrm{NaCl}$ concentrations of 50 , 100, and $150 \mathrm{mM}$, respectively (Fig. 2). LAP mix inoculation significantly increased the radicle length in germinated $R$. sativus seeds by $7.5,1.3,1.2$, and $0.6 \mathrm{~cm}$ under salinity stress of $50,100,150$, and $200 \mathrm{mM} \mathrm{NaCl}$, respectively. Lactobacillus sp. and P. putida inoculation showed higher radicle lengths compared with non-inoculated $R$. sativus seeds but lower than $A$. chroococcum (Table 6). Inoculation by $A$. chroococcum significantly increased the plumule length of the germinated $R$. sativus seeds compared with the non-inoculated control. A. chroococcum enhanced the plumule length by $3.0,0.8$, and $0.6 \mathrm{~cm}$ under salinity stress of 50,100 , and $150 \mathrm{mM} \mathrm{NaCl}$, respectively. However, at $200 \mathrm{mM} \mathrm{NaCl}$, the bacterial inoculation did not show any change or length as compared with the control. This result was similar to that shown by LAP mix inoculants, which increased the plumule length by $2.9,0.8$, and $0.6 \mathrm{~cm}$ at $\mathrm{NaCl}$ treatments of 50,100, and $150 \mathrm{mM}$, respectively (Fig. 3). Lactobacillus sp. increased the plumule length by $2.0 \mathrm{~cm}$ at $50 \mathrm{mM} \mathrm{NaCl}$, and $P$. putida increased the plumule length by $1.0 \mathrm{~cm}$ at the same salinity level. However, all inoculants did not enhance the plumule growth at $200 \mathrm{mM}$ $\mathrm{NaCl}$ (Table 7).

\section{Discussion}

Chinese cabbage (Brassica rapa), lettuce (Lactuca sativa), and radish (Raphanus sativus) are known as main economic plant crops cultivated and used in Asia. Most of the plant species are sensitive to high concentrations of salts in the soil, and that affects the cultivated area steadily. Therefore, salinity is one major severe stress factor affecting crop productivity. In recent years, it has been revealed that bacteria belonging to different genera, such as Rhizobium, Bacillus, Pseudomonas, Burkholderia, Achromobacter, Methylobacterium, and Variovorax, can provide tolerance to host plants against different abiotic stresses [18]. These bacteria can attenuate the environmental stresses in agriculture and can be helpful for mitigating soil salinity. Sadeghi et al. [19] reported increases in the growth of a wheat plant when they inoculated the wheat seedlings with an auxin- and siderophore-producing strain of Streptomyces under saline soil conditions. In this study, L. sativa and R. sativus were used to check the mitigation potential of PGPB upon salinity stress. The influence of the selected PGPR strains on plant growth was investigated under normal (Fig. 4) and stress conditions. The ability of rhizobacteria to enhance plant tolerance and promote growth has been recorded. Salinity level affects essential biochemical processes in plants, such as protein synthesis, photosynthesis, and lipid metabolism [20]. However, most plants have adaptation mechanisms to overcome the deteriorations of salinity, such as regulation and immobilization of metals, stimulation of plant hormones, and changes in photosynthetic pathways. The isolation of

Table 5. Effect of PGPR on seed germination of radish Raphanus sativus under different salinity levels after $96 \mathrm{~h}$.

\begin{tabular}{|c|c|c|c|c|c|}
\hline \multirow{2}{*}{$\mathrm{NaCl}(\mathrm{mM})$} & \multicolumn{5}{|c|}{ Germination rate $(\%)$} \\
\hline & Control & A. chroococcum & Lactobacillus sp. & P. putida & LAP mix \\
\hline 50 & $80 \pm 1.41 \mathrm{ab}$ & $80 \pm 1.41 \mathrm{ab}$ & $80 \pm 1.41 \mathrm{ab}$ & $80 \pm 1.41 \mathrm{ab}$ & $80 \pm 1.41 \mathrm{ab}$ \\
\hline 100 & $80 \pm 1.41 \mathrm{ab}$ & $80 \pm 0.71 a b$ & $95 \pm 0.71 a$ & $80 \pm 0.35 a b$ & $80 \pm 0.57 a b$ \\
\hline 150 & $80 \pm 1.41 a b$ & $75 \pm 0.71 \mathrm{ab}$ & $55 \pm 0.71 b$ & $80 \pm 0.71 \mathrm{ab}$ & $75 \pm 0.71 \mathrm{ab}$ \\
\hline 200 & $50 \pm 1.41 b$ & $50 \pm 1.41 b$ & $50 \pm 0.71 b$ & $50 \pm 1.41 b$ & $60 \pm 1.41 \mathrm{ab}$ \\
\hline
\end{tabular}



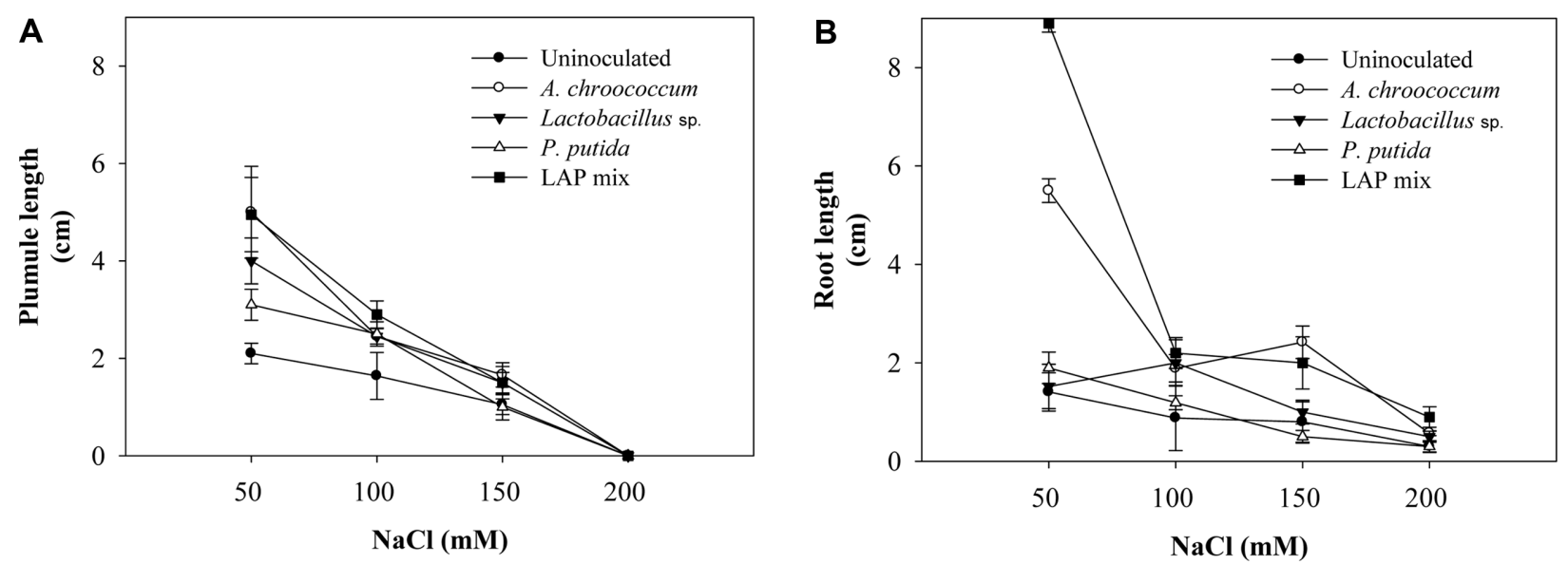

Fig. 2. Inoculation alleviates salinity stress in the early seed germination of radish Raphanus sativus.

(A) Plumule length and (B) root length after $96 \mathrm{~h}$ of different salinity stress and bacterial applications.

indigenous strains from stress-influenced soils and screening on the premise of their stress resistance and PGP qualities might be helpful in the quick determination of effective strains that could be used as bioinoculants for stressed plant crops. According to the results of this study, inoculation of A. chroococcum significantly increased the germination rate of L. sativa seeds by $25 \%, 95 \%$, and $90 \%$ higher than uninoculated seeds at salinity stress of 100, 150, and $200 \mathrm{mM}$ $\mathrm{NaCl}$, respectively. Moreover, Lactobacillus sp. enhanced the seed germination by $25 \%$ and $15 \%$ at $\mathrm{NaCl}$ stress of 100 and $150 \mathrm{mM}$, respectively (Table 5). Rhizobacteria able to conduct positive interactions with plant roots, well-known as plant growth-promoting rhizobacteria, are prospective for their beneficial use in sustainable agriculture. In this study, LAPmix inoculation increased the radicle length of L. sativa seedlings significantly by 2.0 and $0.5 \mathrm{~cm}$ at salinity stress of 50 and $100 \mathrm{mM} \mathrm{NaCl}$, respectively. However, all inoculants could not enhance the radicle length at salinity stresses over $100 \mathrm{mM} \mathrm{NaCl}$ (Table 6). Plant-associated microorganisms can play a significant role in acquiring resistance to abiotic stresses. The rhizosphere, endophytic, and symbiotic bacteria and fungi may act via different mechanisms, such as phytohormone supply, inducing an osmotic response, biosynthesis of siderophores, nutrients uptake, and protection. Inoculation of $A$. chroococcum and LAP mix increased the plumule length of L. sativa germinated seed by 2.0 and $2.3 \mathrm{~cm}$ at $50 \mathrm{mM} \mathrm{NaCl}$, respectively. Lactobacillus sp. inoculation increased the length of plumule by $2.0 \mathrm{~cm}$ at $50 \mathrm{mM}$ of $\mathrm{NaCl}$, and by 0.3 at $100 \mathrm{mM} \mathrm{NaCl}$ higher than the control (Table 7). The $R$. sativus radicle was greatly enhanced by A. chroococcum inoculation, which further increased the radicle length higher than the uninoculated seeds by $4.0,1.0$, and $1.5 \mathrm{~cm}$ at 50,100, and $150 \mathrm{mM} \mathrm{NaCl}$, respectively. LAP mix inoculation significantly improved the radicle length in germinated $R$. sativus seeds by $7.5,1.3,1.2$, and $0.6 \mathrm{~cm}$ under salinity stress of 50,100, 150, and $200 \mathrm{mM} \mathrm{NaCl}$, respectively (Table 6). The rhizo-microorganisms secrets certain compounds on the root tip mucilage, providing a defensive zone and elongating root cells [21]. Dimkpa et al. [22] reported that inoculation of the plant by PGPR enhanced lateral root development owing to higher nitric acid and IAA production, and decreased ethylene-induced stress in plants. In the present results, A. chroococcum enhanced the plumule length by $3.0,0.8$, and $0.6 \mathrm{~cm}$ under salinity stress of 50,100, and $150 \mathrm{mM} \mathrm{NaCl}$, respectively.

Table 6. Effect of PGPR on the root length of radish Raphanus sativus under different salinity levels.

\begin{tabular}{|c|c|c|c|c|c|}
\hline \multirow{2}{*}{$\mathrm{NaCl}(\mathrm{mM})$} & \multicolumn{5}{|c|}{ Radicle length (cm/plant) } \\
\hline & Control & A. chroococcum & Lactobacillus sp. & P.putida & LAP mix \\
\hline 50 & $1.41 \pm 0.39$ efghi & $5.5 \pm 0.24 b$ & $1.52 \pm 0.45 \mathrm{efgh}$ & $1.90 \pm 0.32 \mathrm{def}$ & $8.90 \pm 2.18 a$ \\
\hline 100 & $0.88 \pm 0.66 h i j$ & $1.89 \pm 0.28 \mathrm{defg}$ & $2.0 \pm 0.47 \mathrm{def}$ & $1.19 \pm 0.14$ fghij & $2.20 \pm 0.31 \mathrm{de}$ \\
\hline 150 & $0.80 \pm 0.41 \mathrm{hij}$ & $2.42 \pm 0.33 d$ & $1.0 \pm 0.24 \mathrm{ghij}$ & $0.50 \pm 0.13 j$ & $2.00 \pm 0.53 \mathrm{def}$ \\
\hline 200 & $0.30 \pm 0.12 \mathrm{j}$ & $0.57 \pm 0.05 \mathrm{ij}$ & $0.50 \pm 0.11 \mathrm{j}$ & $0.30 \pm 0.11 \mathrm{j}$ & $0.90 \pm 0.21 \mathrm{hij}$ \\
\hline
\end{tabular}




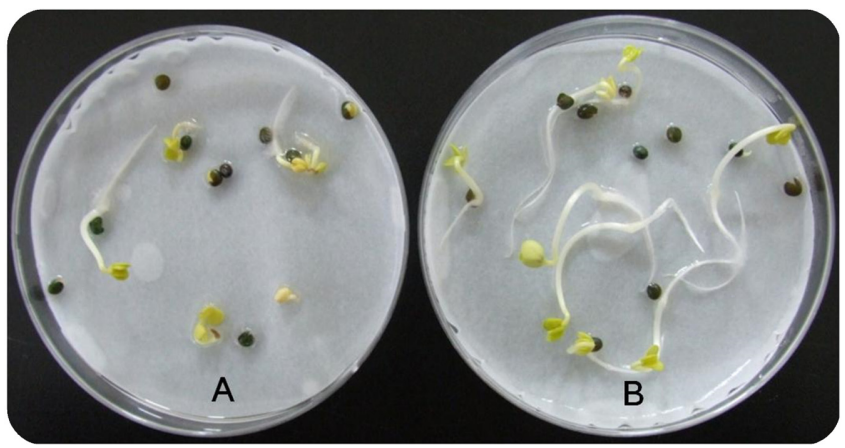

Fig. 3. PGPR effect to mitigate salinity stress of $100 \mathrm{mM} \mathrm{NaCl}$ either for percentage of seed germination or plumule and root lengths of radish (Raphanus sativus) after $96 \mathrm{~h}$ of treatment.

(A) Uninoculated seeds. (B) Inoculated seeds with LAP mix.

LAP mix increased the plumule length of $R$. satious by $2.9,0.8$, and $0.6 \mathrm{~cm}$ at $\mathrm{NaCl}$ treatments of 50,100 , and $150 \mathrm{mM}$, respectively (Table 7). Ethylene plays an important physiological role in plants, either in normal plant growth or in the stressed plant. Ethylene synthesis is highly affected by slight changes in the environmental factors, including light, temperature, and other phytohormones, and its production increases as a response to several stresses, both abiotic and biotic, suggesting that it acts as a bridge between a changing environment and developmental adaptation. The abiotic stress conditions that trigger ethylene synthesis include submergence, heat, shade, exposure to heavy metals and high salt, low nutrient availability, and water deficiency [23]. The ethylene biosynthesis pathway consists of a simple three-step process: methionine is converted into S-adenosyl methionine, which is further converted by ACC-synthases to ACC, the direct precursor of ethylene. Recycling of methylthioadenosine enables rapid ethylene biosynthesis when necessary [24]. Some bacterial species possess the ability to synthesize ACC deaminase that breaks this ACC [25]. Burkholderia spp. can degrade excess amounts of ACC and produce nitrogen and energy as a by-product, consequently reducing the stress

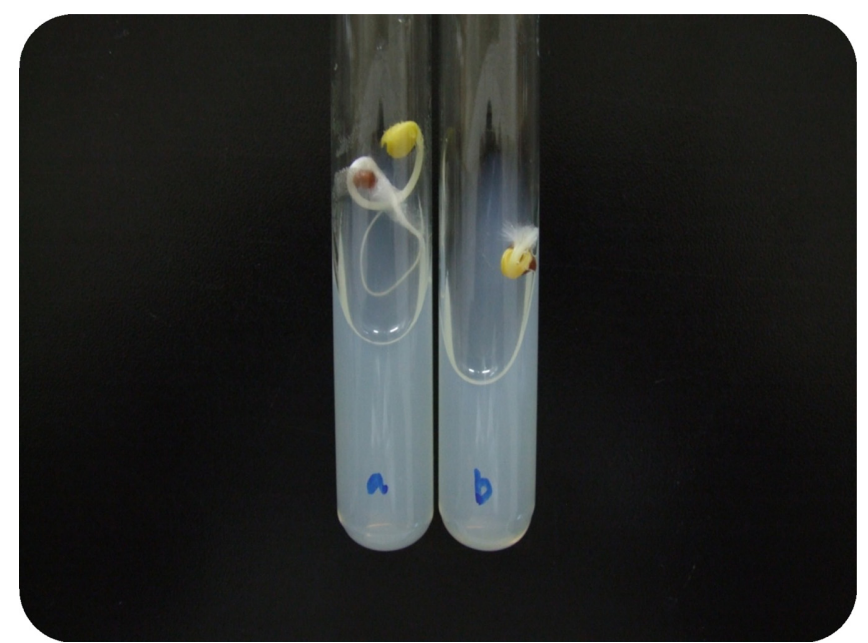

Fig. 4. Effect of PGPR on early seed germination of Chinese cabbage under normal conditions (after $96 \mathrm{~h}$ ).

a: Seeds were inoculated with Lactobacillus sp.; b: Uninoculated seeds.

response and enhancing plant growth [26]. PGPR may improve plant growth, either by enhancing plant tolerance or producing plant growth hormones. In this study, the effects of the PGPR to mitigate the salinity stress on the early germination of plant seeds were tested. The significant differences found in both radicle and plumule lengths of L. sativa and R. sativus may be due to the bacterial inoculation. When plant growth suppression is the result of ethylene stress, PGPR with ACCD can be exploited [27]. ACCD metabolizes ACC, a precursor of ethylene in the biosynthesis pathway, thus limiting the amount of ethylene stress that can be produced [28, 29]. Polyamines secreted by PGPR have also been exposed to mitigate stress ethylene levels and alleviate osmotic stress [30, 31]. PGPR have been demonstrated to activate the synthesis of antioxidants and indole acetic acid, which can stimulate root growth $[28,32,33]$. Recently, PGPR were shown to alter mineral uptake, which results in a favorable increase in the cellular ratio of $\mathrm{K}+/ \mathrm{Na}+$; and elevated generation of quorum-sensing molecules, which can lead to modifications

Table 7. Effect of PGPR on the plumule length of radish Raphanus sativus under different salinity levels.

\begin{tabular}{ccccc}
\hline \multirow{2}{*}{$\mathrm{NaCl}(\mathrm{mM})$} & \multicolumn{3}{c}{ Plumule length (cm/plant) } \\
\cline { 2 - 5 } & Control & A. chroococcum & Lactobacillus sp. & P. putida \\
\hline 50 & $2.1 \pm 0.21 \mathrm{ef}$ & $5.00 \pm 0.94 \mathrm{a}$ & $4.00 \pm 0.47 \mathrm{~b}$ & $3.1 \pm 0.32 \mathrm{c}$ \\
100 & $1.64 \pm 0.48 \mathrm{fg}$ & $2.45 \pm 0.16 \mathrm{de}$ & $2.45 \pm 0.16 \mathrm{de}$ & $2.5 \pm 0.25 \mathrm{de}$ \\
150 & $1.05 \pm 0.20 \mathrm{~h}$ & $1.66 \pm 0.25 \mathrm{fg}$ & $1.5 \pm 0.21 \mathrm{hg}$ & $1.0 \pm 0.27 \mathrm{~h}$ \\
200 & $0.001 \pm 0 \mathrm{~h}$ & $0.001 \pm 0 \mathrm{~h}$ & $0.001 \pm 0 \mathrm{~h}$ & $0.001 \pm 0 \mathrm{~h}$ \\
\hline
\end{tabular}


in the rhizosphere [34-36]. Lactobacillus sp. and A. chroococcum showed remarkable activation either in normal or under stress conditions. Co-inoculation with the three rhizobacterial strains (LAP mix) showed a synergistic impact that improved the early germination of the seeds. The consequences of this investigation are promising for use of rhizobacterial strains that have plant growth-elevating traits to upgrade the plant flexibility against salinity.

\section{Acknowledgments}

This work was carried out with the support of "Cooperative Research Program for Agriculture Science \& Technology Development (Project No. PJ010848)," Rural Development Administration, Republic of Korea.

\section{Conflict of Interest}

The authors have no financial conflicts of interest to declare.

\section{References}

1. Shahbaz M, Ashraf M. 2013. Improving salinity tolerance in cereals. Crit. Rev. Plant Sci. 32: 237-249.

2. Donohue K. 2005. Seeds and seasons: interpreting germination timing in the field. Seed Sci. Res. 15: 175-187.

3. Yang J, Kloepper JW, Ryu CM. 2010. Rhizosphere bacteria help plants tolerate abiotic stress. Trends Plant Sci. 14: 1-4.

4. Bybordi A, Tabatabaei SJ, Ahmadev A. 2010. Effect of salinity on the growth and peroxidase and IAA oxidase activities in canola. J. Food Agric. Environ. 8: 109-112.

5. Bybordi A. 2010. The influence of salt stress on seed germination, growth and yield of canola cultivars. Not. Bot. Horti Agrobot. Cluj Napoca 38: 128-133.

6. Glick BR, Todorovic B, Czarny J, Cheng Z, Duan J, Conkey BM. 2007. Promotion of plant growth by bacterial ACC deaminase. Crit. Rev. Plant Sci. 26: 227-242.

7. Mishra M, Kumar U, Mishra PK, Prakash V. 2010. Efficiency of plant growth promoting rhizobacteria for the enhancement of Cicer arietinum L. growth and germination under salinity. Adv. Biol. Res. 4: 92-96.

8. Glick RB. 2012. Plant growth-promoting bacteria: mechanisms and applications. Scientifica 10: 6064.

9. Turner TR, Ramakrishnan K, Walshaw J, Heavens D, Alston M, Swarbeck D. 2013. Comparative metatranscriptomics reveals kingdom level changes in the rhizosphere microbiome of plants. ISME J. 7: 2248-2258.

10. Hmaeid N, Metoui O, Wali M, Zorrig W, Abdelly C. 2014. Comparative effects of rhizobacteria in promoting growth of Hordeum maritimum L. plants under salt stress. J. Plant Biol.
Res. 3: 37-50.

11. Balloi A, Rolli E, Marasco R. 2010. The role of microorganisms in bioremediation and phytoremediation of polluted and stressed soils. Agrochimica 54: 353-369.

12. Bacilio M, Rodriguez H, Moreno M. 2004. Mitigation of salt stress in wheat seedlings by gfp-tagged Azospirillum lipoferum. Biol. Fertil. Soils 40: 188-193.

13. Hussein KA, Joo JH. 2015. Isolation and characterization of rhizomicrobial isolates for phosphate solubilization and indole acetic acid production. J. Korean Soc. Appl. Biol. Chem. 58: 847-855.

14. McFarland J. 1907. Nephelometer: an instrument for media used for estimating the number of bacteria in suspensions used for calculating the opsonic index and for vaccines. $J$. Am. Med. Assoc. 14: 1176-1178.

15. Kim K, Hwang S, Saravanan VS, Sa T. 2012. Effect of Brevibacterium iodinum RS16 and Methylobacterium oryzae CBMB20 inoculation on seed germination and early growth of maize and sorghum-sudan grass hybrid seedling under different salinity levels. Korean J. Soil Sci. Fert. 45: 51-58.

16. Kader MA. 2005. A comparison of seed germination calculation formulae and the associated interpretation of resulting data. J. Proc. R. Soc. New South Wales 138: 65-75.

17. SAS Institute Inc. 2009. SAS, SAS/STAT 9.1 User's Guide. SAS Institute Inc., Cary, NC, USA.

18. Grover A, Aggarwal PK, Kapoor A, Katiyar-Agarwal S, Agarwal M, Chandramouli A. 2011. Addressing abiotic stresses in agriculture through transgenic technology. Curr. Sci. 84: 355-367.

19. Sadeghi A, Karimi E, Dahazi PA, Javid MG, Dalvand Y, Askari H. 2012. Plant growth promoting activity of an auxin and siderophore producing isolate of Streptomyces under saline soil condition. World J. Microbiol. Biotechnol. 28: 1503-1509.

20. Parida AK, Das AB. 2005. Salt tolerance and salinity effects on plants: a review. Ecotoxicol. Environ. Saf. 60: 324-349.

21. Hardoim PR, van Overbeek SV, van Elsas JD. 2008. Properties of bacterial endophytes and their proposed role in plant growth. Trends Microbiol. 16: 463-471.

22. Dimkpa C, Weinand T, Asch F. 2009. Plant rhizobacteria interactions alleviate abiotic stress conditions. Plant Cell Environ. 32: 1682-1694.

23. Dubois M, Broeck LV, Inzé D. 2018. The pivotal role of ethylene in plant growth. Trends Plant Sci. 23: 311-323.

24. Dubois M, Broeck LV, Inzé D. 2017. Time of day determines Arabidopsis transcriptome and growth dynamics under mild drought. Plant Cell Environ. 40: 180-189.

25. Chen L, Dodd IC, Theobald JC, Belimov AA, Davies WJ. 2013. The rhizobacterium Variovorax paradoxus 5C-2, containing ACC deaminase, promotes growth and development of Arabidopsis thaliana via an ethylene-dependent pathway. J. Exp. Bot. 64: 1565-1573.

26. Onofre-Lemus J, Hernández-Lucas I, Girard L, CaballeroMellado J. 2009. ACC (1-aminocyclopropane-1-carboxylate) 
deaminase activity, a wide spread trait in Burkholderia species, and its growth-promoting effect on tomato plants. Appl. Environ. Microbiol. 75: 6581-6590.

27. Saleem M, Arshad M, Hussain S, Bhatti AS. 2007. Perspective of plant growth promoting rhizobacteria (PGPR) containing ACC deaminase in stress agriculture. J. Ind. Microbiol. Biotechnol. 34: 635-648.

28. Arora NK, Tewari S, Singh S, Lal N, Maheshwari DK. 2012. PGPR for protection of plant health under saline conditions, pp. 239-258. In Maheshwari DK (ed.). Bacteria in Agrobiology: Stress Management. Springer, Berlin.

29. Gerhardt KE, Greenberg BM, Glick BR. 2006. The role of ACC deaminase in facilitating the phytoremediation of organics, metals and salt. Curr. Trends Microbiol. 2: 61-72.

30. Cassán F, Maiale S, Masciarelli O, Vidal A, Luna V, Ruiz O. 2009. Cadaverine production by Azospirillum brasilense and its possible role in plant growth promotion and osmotic stress mitigation. Eur. J. Soil Biol. 45: 12-19.

31. Xie SS, Wu HJ, Zang HY, Wu LM, Zhu QQ, Gao XW. 2014.
Plant growth promotion by spermidine-producing Bacillus subtilis OKB105. Mol. Plant Microbe. Interact. 27: 655-663.

32. Jha Y, Subramanian RB. 2014. PGPR regulate caspase-like activity, programmed cell death, and antioxidant enzyme activity in paddy under salinity. Physiol. Mol. Biol. Plant 20: 201-207.

33. Dodd IC, Pérez-Alfocea F. 2012. Microbial amelioration of crop salinity stress. J. Exp. Bot. 63: 3415-3428.

34. Upadhyay SK, Singh DP. 2015. Effect of salt-tolerant plant growth-promoting rhizobacteria on wheat plants and soil health in a saline environment. Plant Biol. 17: 288-293.

35. Barriuso J, Ramos Solano B, Gutierrez Manero FJ. 2008. Protection against pathogen and salt stress by four plant growth-promoting rhizobacteria isolated from Pinus sp. on Arabidopsis thaliana. Phytopathology 98: 666-672.

36. Yildrim E, Donmez MF, Turan M. 2008. Use of bioinoculants in ameliorative effects on radish plants under salinity stress. J. Plant Nutr. 31: 2059-2074. 